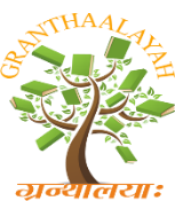

$$
\begin{gathered}
\text { INTERNATIONAL JOURNAL OF RESEARCH } \\
\text { GRANTHAALAYAH } \\
\text { A knowledge Repository }
\end{gathered}
$$

Science

\title{
INVESTIGATION OF THE EFFECT OF BASALT FIBER ON SELF- COMPACTING CONCRETE
}

\author{
Aylin Ozodabas *1 \\ ${ }^{* 1}$ Bilecik Seyh Edebali University Department of Civil Engineering, Bilecik, Turkey
}

\begin{abstract}
Self-compacting concrete is used in many application fields in construction, repair, and maintenance, and reinforcement. Self-settling concretes are advantageous in terms of labor and speed. Self-compacting concrete samples compared to the amount of binder; blast furnace slag 10 $\%$ and $30 \%$, plasticizer additive $2.7 \%$, basalt fiber $1.6 \%$ in samples A and 3.2\% in samples B were used. But basalt fiber was not used in samples $\mathrm{C}$. The plasticizing additive used was kept constant in all samples.

Slump Flow Test, V-funnel, L-box, compressive strength, ultrasonic pulse velocity, water absorption and weight per unit of volume tests were performed and the obtained values were discussed in detail in the discussion and conclusion sections. It has been observed that the use of basalt fiber reduces the workability in fresh concrete but increased the compressive strength values. Samples basalt containing could not provide determined standard values for slump flow and V-funnel and L-box tests. As the use of basalt fiber increased, the viscosity in the concrete decreased. For the samples with $1 \%$ basalt fiber, the pressure strength values decreased by $0.5 \%$ compared to the samples with basalt fiber.
\end{abstract}

Keywords: Basalt Fiber; Plasticizing Additive; Blast Furnace Slag; Self-Compacting Concrete.

Cite This Article: Aylin Ozodabas. (2018). "INVESTIGATION OF THE EFFECT OF BASALT FIBER ON SELF-COMPACTING CONCRETE." International Journal of Research Granthaalayah, 6(12), 38-45. https://doi.org/10.29121/granthaalayah.v6.i12.2018.1075.

\section{Introduction}

Self-Compacting Concrete (SCC) is a special type high performance concrete that has high fluidity and workability properties due to its lower water to cement ratio which leads to rapid strength development and high durability performances. SCC fills the framework without any vibration process and it can be easily placed in the dense reinforcement. This concrete minimizes and prevents possible mistakes such as air gaps in concrete during the placement and compaction process. Also, SCC shows better performances in terms of segregation and bleeding. Because of these advantages, it becomes one of the most popular construction materials [1]. 
Architectural concrete is a fantastic topic. Architectural concrete is nonstructural or structural concrete that will be perennially exposed to view and needs special attention for this reason to material uniformity, forming, placing, and finishing to obtain the desired architectural and decorative appearance [2]. The use of slag reduced the rate of plasticizer additive [3] The use of metakaolin increased the process ability of mixtures substituted in the proportional proportions with the superplasticizer used as a chemical additive [4]. Results highlight that self-compacting characteristics are maintained when recycled aggregates are utilized and their good quality promotes high mechanical properties [5]. The influence of nano-silica (NS), carbon nano-tube (CNT) and fly ash (FA) as solo, binary or ternary combination on fresh and hardened properties of self-compacting concretes. CNT resulted in more ductile concrete with higher energy-absorbing capacity [6]. To use a type of concrete, which does not need conventional curing, self-curing concrete can be used. The combination of those two types together provides a suitable solution for the curing and compacting processes. g. Curing agents reduce the water evaporation from selfcompacting concrete, and hence increase the water retention capacity of self-compacting concretes with sufficient hardened concrete properties [7]. In this work, a low Portland cement composition of SCC, with added metakaolin and fly ash (binary and ternary blended cements) was studied to evaluate its rheological and mechanical properties. The results show that it is feasible to produce low strength SCC, with the necessary fluidity and reduced binder consumption, when mineral additions of metakaolin and fly ash are used. This makes SCC more efficient, with important reductions in costs and environmental impact [8]. The degree of chloride attack is determined by evaluating the reduction in compressive strength split tensile strength and percentage loss of weight of specimen. From the test results it is observed that maximum compressive strength and split tensile strength were achieved for $1 \%$ of plastic fiber [9].

The application of byproducts or waste materials as cement substitutes in SCC can enhance its mechanical performance. Rice husk ash (RHA) is one of the highly reactive byproducts. The pozzolanic performance of RHA due to high silica content makes it a suitable supplementary cementitious material for being used in SCC. The test results showed that the workability of SCC containing RHA is decreased by increasing the RHA replacement ratio. On the contrary, compressive strength, modulus of elasticity, and splitting tensile strength increase with increasing the percentage of RHA up to 5\% replacement [10].

While the basalt fibers are produced, the temperature during the filming of the fibers also has a significant effect on the mechanical properties to be obtained. The tensile strength of the fiber obtained from the fibers obtained as the temperature increases for the $1200-1400{ }^{\circ} \mathrm{C}$ range tends to increase from $1.5 \mathrm{GPa}$ to $2.9 \mathrm{GPa}$ [11]. The use of basalt fiber in the production of selfcompacting concrete (SCC) has been studied to identify how the fresh and hardened properties of SCC are affected by the addition of fiber. The results reveal that the use of basalt fiber decreases the workability but improves the mechanical properties of SCC. Whereas, the highest compressive strength $(91.15 \mathrm{MPa})$ is obtained from the samples containing the fiber content of $0.1 \%$ for the utilized fiber lengths of $12 \mathrm{~mm}$ and $24 \mathrm{~mm}$. The resulted compressive strength of these samples are about $9.5 \%$ higher than the control sample [12].

In this study, the effect of basalt fiber on self-compacting concrete was investigated. 


\section{Materials and Method}

\subsection{Aggregate}

Crushed stone was used as aggregate. The sieve ranges are selected as 0-5, 5-12 and 12-22 mm.

\subsection{Cement}

CEM I 42.5 class Portland cement supplied from Bilecik Sançim cement plant was used as cement.

\subsection{Chemical Additive}

High water reducer, hyper plasticizer "Glenium C 303" was used as chemical additive. It was obtained from Sika Building Chemicals Incorporated Company.

\subsection{Blast Furnace Slag}

The blast furnace slag obtained from the Karabük Karçimsa cement plant was used.

\subsection{Basalt Fiber}

The chopped basalt fiber obtained from the Dost chemical company was used.

\subsection{Concrete Samples Preparations}

Concrete mixture calculation was made according to Turkish standard 802. The mixing ratios are given in Table 1.

Table 1: Concrete mixing ratios

\begin{tabular}{|l|l|l|l|l|l|l|l|}
\hline & Cement & $\begin{array}{l}\text { Fine } \\
\text { Aggregate }\end{array}$ & $\begin{array}{l}\text { Coarse } \\
\text { Aggregate }\end{array}$ & Water & $\begin{array}{l}\text { Chemical } \\
\text { Additive }\end{array}$ & $\begin{array}{l}\text { Blast } \\
\text { Furnace } \\
\text { Slag }\end{array}$ & $\begin{array}{l}\text { Basalt } \\
\text { Fiber }\end{array}$ \\
\hline A 10\% & 3810 & 5920 & 8030 & 1820 & 114 & 423 & 69,75 \\
\hline A 30\% & 2960 & 5920 & 8030 & 1820 & 114 & 1269 & 69,75 \\
\hline B 10\% & 3810 & 5920 & 8030 & 1820 & 114 & 423 & 139,5 \\
\hline B 10\% & 2960 & 5920 & 8030 & 1820 & 114 & 1269 & 139,5 \\
\hline C 10\% & 3810 & 5920 & 8030 & 1820 & 114 & 426 & 0 \\
\hline C 30\% & 2960 & 5920 & 8030 & 1820 & 114 & 1269 & 0 \\
\hline
\end{tabular}

\subsection{Experiments}

\subsubsection{Slump Flow Test}

Slump flow test was made according to Turkish Standard TS EN 12350-5. 


\subsubsection{Funnel Test}

V funnel test was made according to Turkish Standard TS EN 12350-9.

\subsubsection{Box Test}

L box test was made according to Turkish Standard TS EN 12350-10.

\subsubsection{Compressive Strength Test}

Compressive strength test was made Turkish Standard TS EN 12390-3.

\subsubsection{Ultrasonic Pulse Velocity Test}

Ultrasonic pulse velocity test was made Turkish Standard TS EN 12504-4.

\section{Results and Discussion}

\subsection{Results of Experiments}

According to TS EN 12350-5, the spreading speed of fresh concrete should not be less than 2 seconds and no more than 5 seconds. As a result of the tests carried out according to these conditions, the control samples gave the results which were suitable for the conditions, but the workability decreased and the result was negative as seen in Table 2 in the samples using basalt fiber.

Table 2: Slump flow test

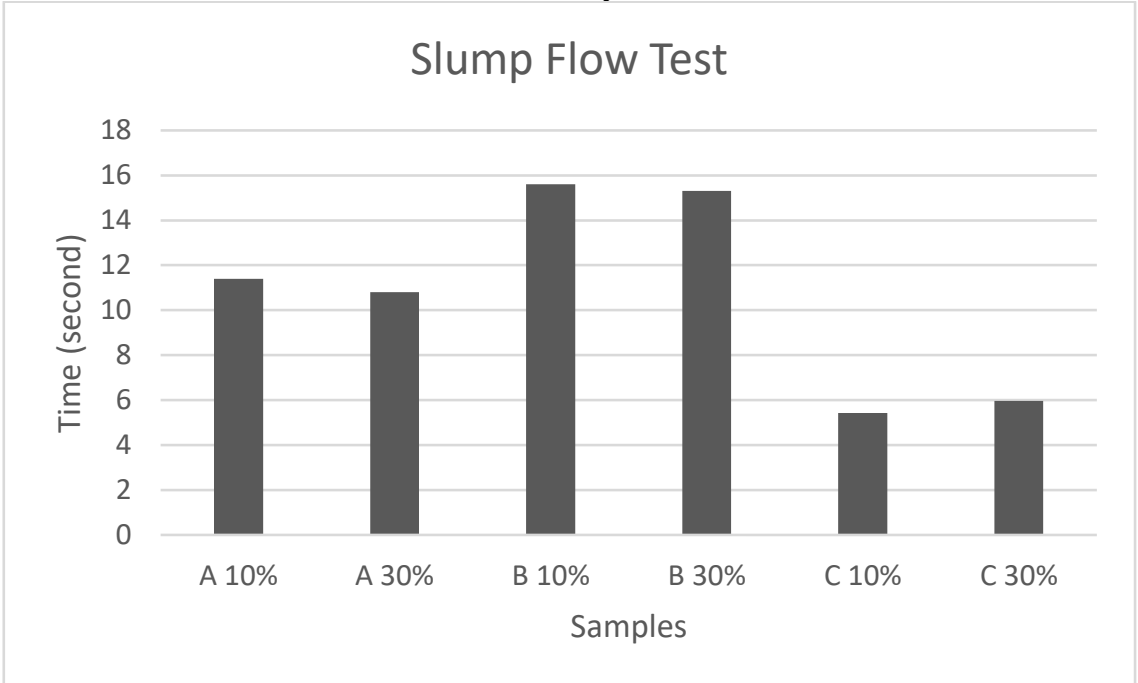

According to TS EN 12350-9, fresh concrete must flow in the range of 9-25 sec. According to TS EN 12350-9, fresh concrete must flow in the range of 9-25 sec. It has been observed that all samples provide the conditions. In addition, $10 \%$ blast furnace slag concrete produced better results than $30 \%$ blast furnace slag concrete and increased blast furnace slag rate gave negative results. The results are given in Table 3 . 
Table 3: V Funnel test

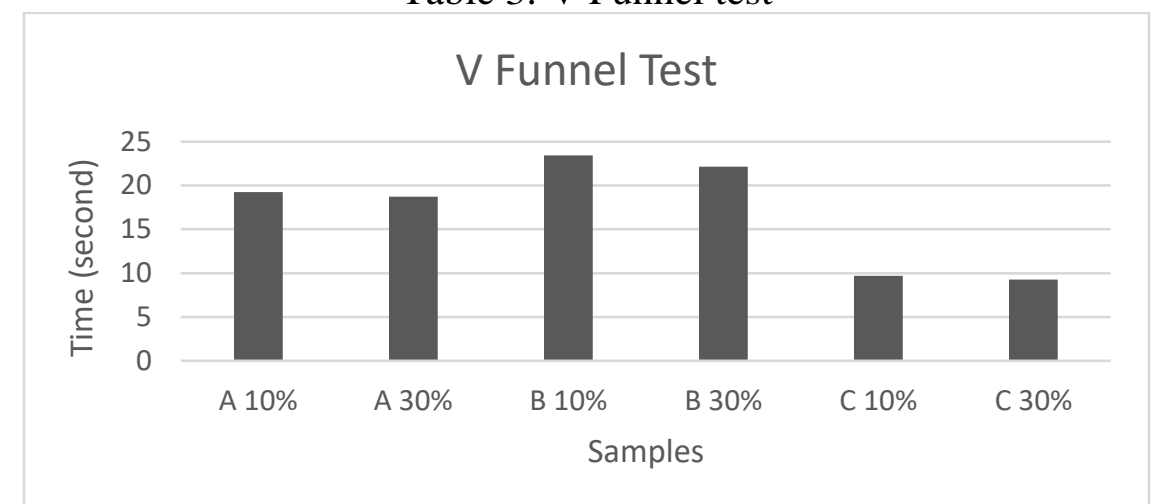

According to TS EN 12350-10 H2 / H1: 1, 0.5\% basalt fiber samples were partially better than $1 \%$ basalt samples. However, the values were below the standard value and as a result of the basalt fiber negatively affected the performance of fresh concrete and the results are shown in Table 4.

Table 4: L Box test

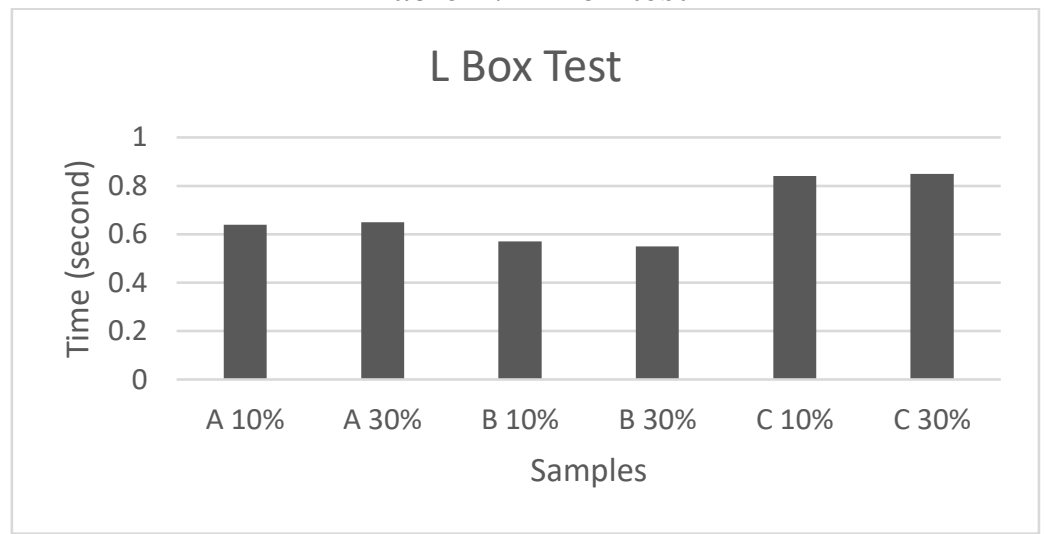

As a result of the tests carried out according to TS EN 12390-3, higher compressive strength values were obtained with $0.5 \%$ basalt fiber concretes compared to $1 \%$ basalt fiber concretes. The results are given in Table5.

Table 5: Compressive strength

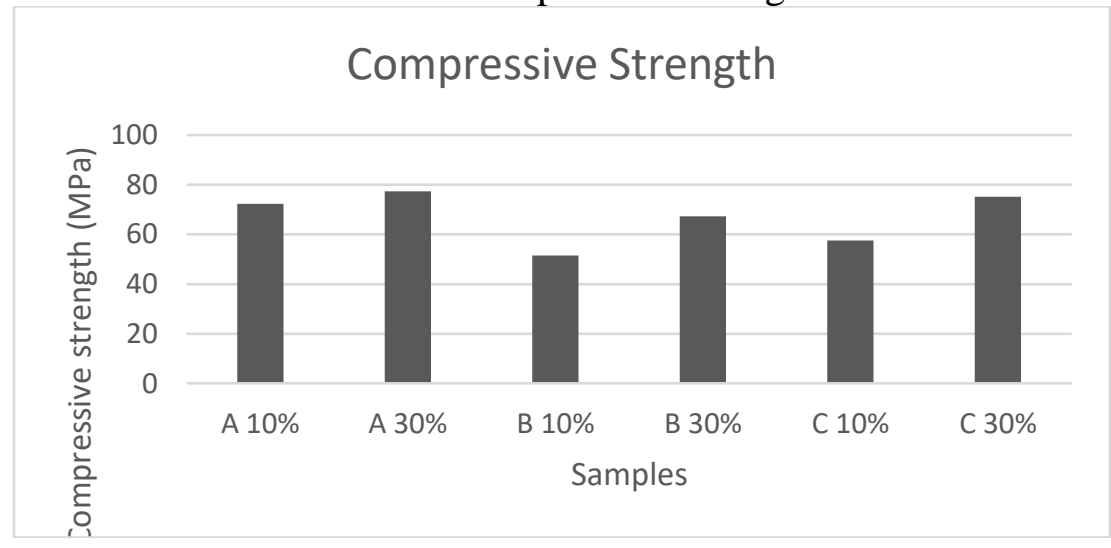

As a result of the experiments carried out according to TS EN 12504-4, it was observed that the sound velocity of the samples used in the basalt fiber was spread more slowly. The increase in the use of basalt fiber has slowed the spread of sound velocity. As a result, the sound velocity of the 
samples using $1 \%$ basalt fiber was found to be better than the samples with $0.5 \%$ basalt fiber. The results are given in Table 6.

Table 6: Ultrasonic pulse velocity test

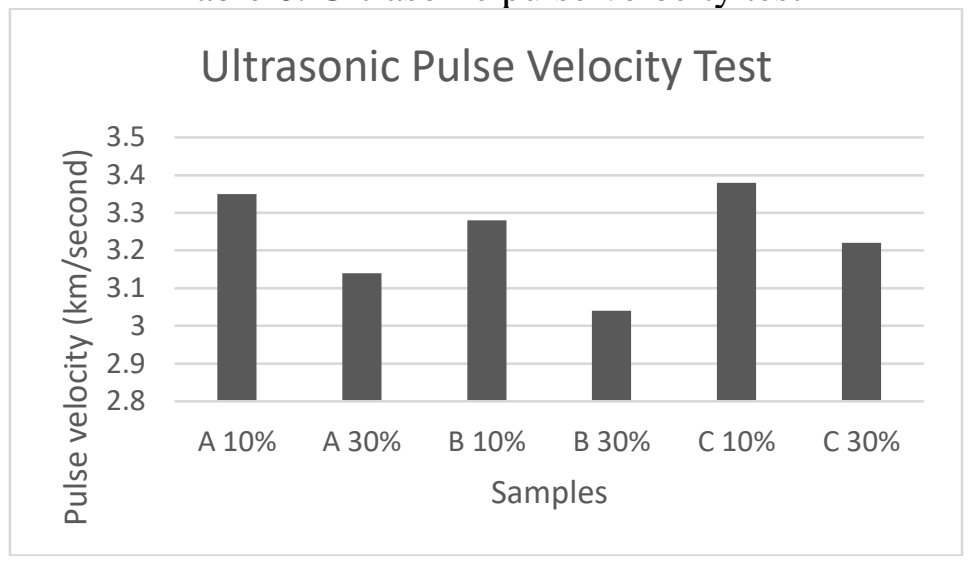

Water absorption test results showed better results in basalt samples. Samples with low percentage of blast furnace slag and basalt fiber ratio have better water absorption values than other samples. Water absorption values are given in Table 7.

Table 7: Water absorption test

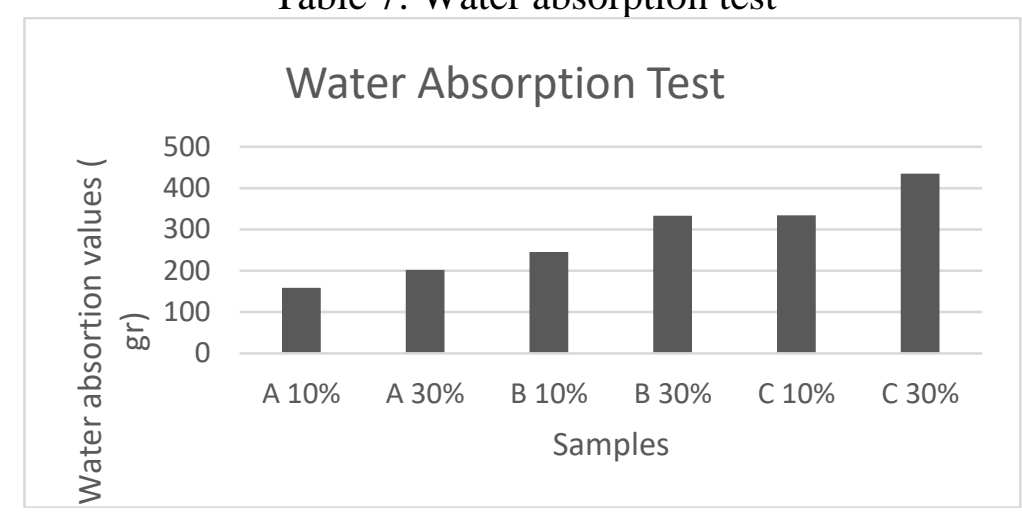

It was determined that the unit weight of the basalt fiber concretes was very high. The results are shown in Table 8.

Table 8: Weight per unit of volume

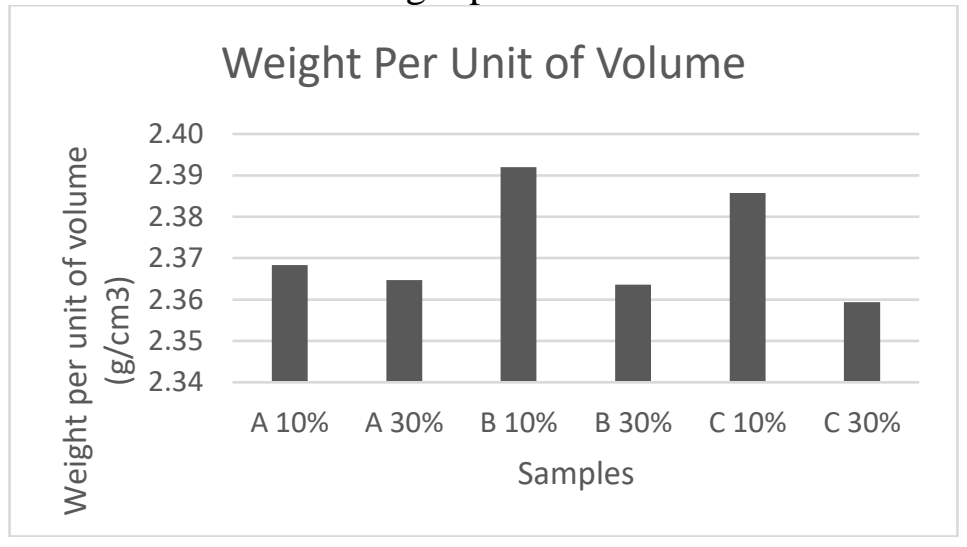


Samples with basalt fiber content could not provide a $50 \mathrm{~cm}$ diameter width representing the standard spreading time $\mathrm{T} 50$ and the $\mathrm{V}$ funnel flow time. In the standard cure conditions, it was observed that 28 days compressive strength values of basalt fiber reinforcement decreased according to the control samples. Ultrasonic speed measurement results showed a positive result in contrast to compressive strength. After 28 days of curing, the samples containing basalt fiber gave better values than the control samples.

\section{Conclusions}

- As a result of the slump flow and V-funnel tests, the best values were obtained from the witness sample $\mathrm{C} 10 \%$. The best value obtained as a result of the L-box test was sample B $30 \%$.

- The best compressive strength was obtained from the blast furnace slag witness sample with $\mathrm{C} \% 30$ content.

- The best ultrasonic pulse velocity test result was obtained witness sample $\mathrm{C} 10 \%$ with the blast furnace slag containing.

- The best water absorption value was obtained from the blast furnace slag sample with A $\% 10$.

- In unit volume weight tests; sample B $10 \%$, with a maximum unit weight, the lowest sample weight is $\mathrm{C}$, which is $10 \%$.

- As a result of the studies and experiments, it was observed that the basalt fibers decreased the workability of the fresh concrete and increased the compressive strength values.

\section{Acknowledgements}

The facilities of the civil engineering laboratories of Bilecik Şeyh Edebali University were used.

\section{References}

[1] A. Ghezal and K. H. Khayat, "Optimizing self-consolidating concrete with limestone filler by using statistical factorial design methods," ACI Mater. J., vol. 99, no. 3, pp. 264-272, 2002.

[2] M. Uysal, "The Use of Waste Maroon Marble Powder and Iron Oxide Pigment in the Production of Coloured Self-Compacting Concrete," Adv. Civ. Eng., vol. 2018, 2018.

[3] Yalçınkaya Çağlar, "An investigation on the mechanical, durability and microstructure properties of fiber reinforced self-compacting concrete with mineral powders," 2011.

[4] Melek Müge Tevrizci, "AN INVESTIGATION ON THE DURABILITY PROPERTIES OF MORTARS INCLUDING METAKAOLIN,” Dokuz Eylul University, 2010.

[5] S. Manzi, C. Mazzotti, and M. Chiara Bignozzi, "Self-compacting concrete with recycled concrete aggregate: Study of the long-term properties," Constr. Build. Mater., vol. 157, pp. 582-590, 2017.

[6] A. C. Aydin, V. J. Nasl, and T. Kotan, "The synergic influence of nano-silica and carbon nano tube on self-compacting concrete," J. Build. Eng., vol. 20, no. April, pp. 467-475, 2018.

[7] M. M. Kamal, M. A. Safan, A. A. Bashandy, and A. M. Khalil, "Experimental investigation on the behavior of normal strength and high strength self-curing self-compacting concrete," J. Build. Eng., vol. 16, no. December 2017, pp. 79-93, 2018.

[8] F. Pelisser, A. Vieira, and A. M. Bernardin, "Efficient self-compacting concrete with low cement consumption,” J. Clean. Prod., vol. 175, pp. 324-332, 2018. 
[9] G. S. Vijaya, V. G. Ghorpade, and H. Sudarsana Rao, "The Behaviour of Self Compacting Concrete with Waste Plastic Fibers When Subjected to Chloride Attack.," Mater. Today Proc., vol. 5, no. 1, pp. 1501-1508, 2018.

[10] E. Molaei Raisi, J. Vaseghi Amiri, and M. R. Davoodi, "Mechanical performance of selfcompacting concrete incorporating rice husk ash," Constr. Build. Mater., vol. 177, pp. 148-157, 2018.

[11] A. D. Murray, Basalt fibres for high-performance composites. 2008.

[12] Z. Algin and M. Ozen, "The properties of chopped basalt fibre reinforced self-compacting concrete," Constr. Build. Mater., vol. 186, pp. 678-685, 2018.

*Corresponding author.

E-mail address: aylin.ozodabas@ bilecik.edu.tr 